\title{
Change of Diet, Plasma Lipids, Lipoproteins, and Fatty Acids during Ramadan: A Controversial Association of the Considered Ramadan Model with Atherosclerosis Risk
}

\author{
Ahmed Barkia',2, Kamel Mohamed', Maha Smaoui ${ }^{3}$, Nouri Zouari', \\ Mohamed Hammami ${ }^{3}$, and Moncef $\mathrm{Nasri}^{2}$ \\ 'Ecole Supérieure des Sciences et Techniques de la Santé, Sfax, Tunisie, 'Laboratoire de Génie Enzymatique et de Microbiologie, \\ Ecole Nationale d'Ingénieurs, Sfax, Tunisie, 'aboratoire de Biochimie, UR « Nutrition Humaine et Désordres Métaboliques » Faculté \\ de, Médecine Monastir, Tunisie, and ${ }^{4}$ Service Exploration Fonctionnelle, Hôpital Universitaire Habib Bourguiba, Sfax, Tunisie
}

\begin{abstract}
Different Islamic populations have different alimentary habits, notably during Ramadan. The paper reports the change of diet, lipids, and lipoproteins produced during Ramadan in one Tunisian population. During Ramadan, the study subjects consumed more proteins, cholesterol, vitamin $\mathrm{E}(\mathrm{p}<0.01)$, and polyunsaturated fatty acids $(\mathrm{p}<0.05)$. At the same time, they exhibited an increase in total cholesterol, low-density lipoprotein-cholesterol $(\mathrm{p}<0.01)$ and apoprotein $\mathrm{B}(\mathrm{p}<0.05)$ and a decrease in the ratio of apoprotein AI to apoprotein $B(p<0.01)$. All assayed saturated fatty acids were unaffected by Ramadan fasting while three unsaturated fatty acids (C18:1cis9, C18:2n-6, and C30:4n-6) increased significantly. A return to the habitual diet for a four-week period was not sufficient to restore the pre-fasting patterns. For the study subjects, Ramadan was clearly associated with a change of diet and biochemical profile but its effective impact on atherosclerosis risk was unclear, perhaps, because other non-alimentary changes ought to be considered too. Future studies considering the no-alimentary factors, such as sleep and physical activity, would be useful to clarify the contribution of dietary change in the observed modification of biological profile.
\end{abstract}

Key words: Atherosclerosis; Diet; Fasting; Fatty acids; Lipoproteins; Ramadan; Tunisia

\section{INTRODUCTION}

Fasting Ramadan is a religious practice respected by a large majority of Muslims, and it is associated with the decrease in the number of meals and the eating pattern which are two metabolically-active parameters $(1,2)$. Consequently, the observed change of biologic profile accompanying the fast of Ramadan is not surprising. However, examination of data revealed that the impact of Ramadan fasting on the health is not same in different populations of Muslims (2-13). In particular, its impact on the atherosclerosis risk varies from one case to another of practising Muslim populations. While fasting is accompanied by an increase of antiatherogenic biochemical parameters [high-density lipoprotein-

Correspondence and reprint requests should be addressed to:

Dr. Barkia Ahmed

Ecole Supérieure des Sciences et Techniques

de la Santé de Sfax

Tunisia

Email: ahmedbarkia_lgem@yahoo.fr cholesterol (HDL-cholesterol) and apolipoprotein (apo) AI] and/or a decrease of atherogenic parameters [triglycerides (TG), total cholesterol (TC), apoprotein (apo) B, and low-density lipoproteincholesterol (LDL-cholesterol)] in certain practising Islamic populations (3-9), it has an opposite effect (10-12) or no impact (13) on other Muslim populations. This discrepancy could be attributed to different ethnic groups and physical activity and also to consumption of different alimentary products due to different physiopathological conditions and geographical zones, or different seasons in which Ramadan takes place.

The role of dietary fat composition in relation to risk of cardiovascular diseases (CVDs) has been a subject of intense debate for some years. While high intakes of saturated fatty acids (SFAs) are known to raise LDL-cholesterol and atherosclerosis risk, intakes of polyunsaturated fatty acids (PUFAs) (n-6 and n-3) are inversely associated with CVDs $(1,14,15)$. 
Available evidence suggests that both lipoprotein oxidative modification and physiological functions, such as blood pressure and platelet aggregation and adhesion, are key mechanisms linked to the development of atherosclerosis and its associated complications, such as CVDs. These two phenomena are influenced by the high intake of PUFAs. In fact, PUFAs are, on one hand, highly sensitive to oxidation $(16,17)$, and on other hand, these are the precursors of active substances (prostaglandins) governing the platelet function and blood pressure. Consequently, the intake of an adequate quantity and/or quality of fatty acids and antioxidant nutriments is necessary to combat atherosclerosis.

The fatty acid composition of total plasma lipids is a reliable marker of alimentary fatty acids $(18,19)$. Then, the study of the plasma fatty acid profile could inform us about the quality of diet. Besides, the existence of a relationship between patterns of plasma fatty acid composition and arterial stiffness has been reported (20). Despite the possible impact of the study of plasma lipid composition, studies on plasma fatty acid composition are sparse. Particularly, the effect of fasting Ramadan on the composition of plasma fatty acids has never been examined.

In Tunisia, Ramadan is always associated with an increased consumption of fruits, salads, eggs, milk, and other dairy products. The changes of diet and several lipid and lipoprotein parameters, including the pattern of plasma fatty acids, have been investigated in subjects from the same area and same socioeconomic level. The findings are presented in this paper.

\section{MATERIALS AND METHODS}

\section{Subjects}

Initially, the number of volunteer subjects was 36 (22 males and 14 females) but only 25 (19 males and 6 females) aged 22-55 years completed the full protocol. All the subjects were from Sfax city (a coastal Tunisian city) and were the staff of the Faculty of Medicine or that of the hospital. All these subjects had a normal glycaemia and body mass index (BMI), and none of them had a history of metabolic disease in their immediate family lineage.

\section{Alimentary survey}

Before Ramadan, the subjects provided a written description of 4-6 diets. The average of these diets was used as the habitual one. During Ramadan, twice a week, each subject recorded the approximate quantities of food eaten. The total Ramadan diet was the average of the eight recorded meals. The nutrient intakes were calculated using the Nutritionist IV Computer Analysis software (version 3.1) (Nutritionist IV Computer Analysis Program, 1994, N2 Computing, Hearst Corp. Salem, OR, USA).

\section{Blood-collection samples}

Before midday and approximately 9-10 hours after the last meal taken by the subjects, $10 \mathrm{~mL}$ of blood samples were drawn by venipuncture into tubes containing $0.01 \mathrm{mM}$ of ethylene diamine tetraacetic, $2 \mu \mathrm{g} / \mathrm{mL}$ of sodium azoture, and $5 \mu \mathrm{g} /$ $\mathrm{mL}$ of gentamicin. Plasmas were obtained by centrifugation at 3,000 rpm for 15 minutes at $6-8{ }^{\circ} \mathrm{C}$. Glycaemia was determined immediately using a glucose oxidase method. Then, the plasmas were fractionated and placed at $-20{ }^{\circ} \mathrm{C}$ until they were used again. This operation was carried out four times. The first time goes from two days before Ramadan to the first day of this month. The second and third samples were taken respectively after two weeks and four weeks of Ramadan. The fourth sample was taken one month after Ramadan.

\section{Analysis of plasma lipids, lipoproteins, and apolipoproteins}

HDL fraction was obtained by precipitation of apoBcontaining lipoproteins using phosphotungstic acid (Bio-Merieux, France). The absence of apoB in this fraction was confirmed immunologically using ready commercially-available plates (Sebia, France). TG, TC, and HDL-cholesterol were quantified by standard enzymatic techniques with spectrophotometric detection. Apolipoprotein AI and B were quantified by electrophoretic immunodiffusion using ready commercially-available plates (Sebia, France).

\section{Plasma fatty acid profile}

The fatty acid composition of lipids was extracted from the plasma following the method of Folch et al. (21). Samples were dried up and esterified by heating these at $80^{\circ} \mathrm{C}$ for two hours with methanol containing $2 \%$ concentrated $\mathrm{H}_{2} \mathrm{SO}_{4}$. The fatty acid methyl esters of each sample were injected into a Hewlett Packard HP 5890 Series II gas chromatograph (Hewlett Packard, Palo Alto, Calif) equipped with a flame ionization detector and a polar fused silica capillary column HP-Innowax with crosslinked PEG, Carbowax $20 \mathrm{M}(30 \mathrm{~m} \times 0.25 \mathrm{~mm}$ ID and $0.25 \mu \mathrm{m}$ as film thickness). The oven temperature was programmed to increase from $180{ }^{\circ} \mathrm{C}$ to $250{ }^{\circ} \mathrm{C}$ at a rate of $10^{\circ} \mathrm{C}$ per minute, and the injector and the detector temperature was $220^{\circ} \mathrm{C}$ and $280^{\circ} \mathrm{C}$ respectively. Carrier gas was nitrogen (flow rate of $1 \mathrm{~mL} /$ minute). Each fatty acid concentration was expressed in absolute value $(\mathrm{g} / 100 \mathrm{~g})$ following 
an internal standard method using C17:0. Three injections per sample were performed.

\section{Statistical analysis}

Data were expressed as means (standard deviation). The average concentrations obtained in the two subject groups were compared using Student's $t$-test while the percentages were compared using the $\chi^{2}$ test. The differences were considered significant at $\mathrm{p}<0.05$.

\section{Ethical approval}

A medical committee of the Sfax University Teaching Hospital approved the study, and informed consent was obtained from each participant after a full explanation of the study.

\section{RESULTS}

\section{Characteristics of study subjects}

Age, BMI, and fasting glycaemia are summarized in Table 1. Glycaemia was absolutely unchanged while BMI increased from $26.4 \pm 4.2 \mathrm{~kg} / \mathrm{m}^{2}$ to $27.9 \pm 1.8 \mathrm{~kg} /$ $\mathrm{m}^{2}$. One month after Ramadan, BMI decreased but remained relatively higher than the pre-Ramadan's BMI.

\section{Characteristics of diets}

As shown in Table 2, Ramadan fasting was associated with an increase of the estimated total energy consumption $(+5.6 \%)$. The intake of proteins, cho-
Table 1. Characteristics of recruited subjects: age; BMI, and glycaemia before Ramadan, end of Ramadan, and after Ramadan

\begin{tabular}{|l|l|}
\hline Number & 25 \\
Sex (male/female) & $19 / 6$ \\
Mean age $($ range) & $42(22-55)$ years \\
BMI $\left(\mathrm{kg} / \mathrm{m}^{2}\right): \mathrm{BR} /$ & $26.4 \pm 4.2 / 27.9 \pm$ \\
ER/AR & $1.8 / 27.1 \pm 2.6$ \\
Glucose $(\mathrm{mmol} / \mathrm{L}):$ & $4.7 \pm 0.8 / 4.9 \pm$ \\
BR/ER/AR & $0.9 / 4.7 \pm 0.9$ \\
\hline
\end{tabular}

$\mathrm{AR}=$ After Ramadan; $\mathrm{BMI}=$ Body mass index; $\mathrm{BR}=$ Before Ramadan; ER=End of Ramadan

lesterol, and vitamin $\mathrm{E}(\mathrm{p}<0.01)$ and PUFAs $(\mathrm{p}<0.05)$ increased while the consumption of carbohydrates decreased $(p<0.01)$. In addition, the ratio of PUFAs to SFAs increased significantly $(\mathrm{p}<0.05)$ during Ramadan.

\section{Pattern of total plasma fatty acids}

Table 3 shows that none of the quantified SFA changed even at the end of Ramadan. However, two weeks of Ramadan fasting were sufficient to increase three polyunsaturated fatty acids: C18:1cis, C18:2n-6 (p<0.05), and C20:4n-6 (p<0.01) in a significant way. No change of MUFA/PUFAs (49-50\%) and of oleic acid/PUFAs (43-44\%) was observed. The continuation of Ramadan practice more than two weeks did not have any additional effect. One month after Ramadan, these fatty acids were still high but the C18:1 cis level did not differ significantly from its pre-fasting values.

\begin{tabular}{|c|c|c|}
\hline Nutrient & Ramadan diet & Habitual diet \\
\hline Energy (kcal/day) & $2,447 \pm 329$ & $2,585 \pm 339 \mathrm{NS}$ \\
\hline \multicolumn{3}{|c|}{$\%$ of energy contributed by } \\
\hline Proteins & $12.2 \pm 1.8$ & $15.6 \pm 2.0^{\star *}$ \\
\hline Fats & $34.4 \pm 9.4$ & $37.2 \pm 10.1$ \\
\hline Carbohydrates & $52.9 \pm 4.6$ & $47.2 \pm 2.9^{\star *}$ \\
\hline \multicolumn{3}{|l|}{ Nutrients intake } \\
\hline Cholesterol (mg/day) & $250.9 \pm 125.2$ & $529.0 \pm 147.3^{* *}$ \\
\hline SFA (g/day) & $28.5 \pm 8.7$ & $31.5 \pm 8.0 \mathrm{NS}$ \\
\hline MUFA (g/day) & $47.8 \pm 13.4$ & $49.3 \pm 13.8 \mathrm{NS}$ \\
\hline PUFA (g/day) & $20.1 \pm 11.3$ & $30.9 \pm 8.7^{*}$ \\
\hline PUFA/SFA (\%) & $0.7 \pm 0.4$ & $1.0 \pm 0.3^{*}$ \\
\hline Fibre (g/day) & $16.5 \pm 4.7$ & $18.7 \pm 6.6 \mathrm{NS}$ \\
\hline Vitamin E (mg/day) & $6.7 \pm 4.7$ & $9.6 \pm 1.6^{\star \star}$ \\
\hline Vitamin C (mg/day) & $53.7 \pm 46.9$ & $45.3 \pm 20.3 \mathrm{NS}$ \\
\hline
\end{tabular}




\begin{tabular}{|c|c|c|c|c|}
\hline Parameter & $\mathrm{BR}$ & R (2 weeks) & R (4 weeks) & AR (4 weeks) \\
\hline C14:0 & $11.7 \pm 6.8$ & $13.5 \pm 6.3$ & $13.5 \pm 6.7$ & $13.4 \pm 6.5$ \\
\hline C14:1 & $1.3 \pm 1.8$ & $1.6 \pm 1.8$ & $1.2 \pm 0.8$ & $1.1 \pm 0.9$ \\
\hline C16:0 & $416.0 \pm 125.5$ & $507.0 \pm 138.2$ & $444.2 \pm 110.5$ & $444.4 \pm 96.0$ \\
\hline C16:1 & $23.3 \pm 16.5$ & $27.3 \pm 12.1$ & $24.1 \pm 17.8$ & $21.7 \pm 9.6$ \\
\hline C18:0 & $124.1 \pm 30.5$ & $139.8 \pm 35.7$ & $132.7 \pm 25.3$ & $121.9 \pm 25.4$ \\
\hline C18:1 cis & $351.8 \pm 94.3$ & $453.2 \pm 143.2^{*}$ & $439.9 \pm 140.0^{*}$ & $402.6 \pm 87.2$ \\
\hline C18:1 trans & $26.5 \pm 8.9$ & $27.4 \pm 8.9$ & $32.4 \pm 15.1$ & $33.2 \pm 12.0$ \\
\hline C18:2n-6 & $589.8 \pm 174.4$ & $715.8 \pm 160.2^{*}$ & $702.6 \pm 145.0^{*}$ & $680.2 \pm 62.5^{*}$ \\
\hline C18:3n-3 & $12.1 \pm 18.9$ & $14.9 \pm 8.7$ & $12.1 \pm 4.5$ & $11.2 \pm 7.8$ \\
\hline C20:0 & $2.8 \pm 1.6$ & $3.8 \pm 3.1$ & $3.4 \pm 1.6$ & $2.3 \pm 1.6$ \\
\hline C20:1n-9 & $4.6 \pm 3.7$ & $4.9 \pm 2.5$ & $5.0 \pm 3.8$ & $4.6 \pm 1.7$ \\
\hline$C 20: 2 n-6$ & $2.4 \pm 2.9$ & $1.3 \pm 1.2$ & $1.1 \pm 1.0$ & $3.5 \pm 2.9$ \\
\hline$C 20: 3 n-6$ & $1.3 \pm 1.7$ & $2.0 \pm 1.1$ & $2.2 \pm 2.5$ & $1.5 \pm 0.8$ \\
\hline C20:4n-6 & $98.1 \pm 36.5$ & $133.5 \pm 41.9^{\star *}$ & $146.2 \pm 51.9^{\star *}$ & $126.0 \pm 79.5^{*}$ \\
\hline C22:0 & $16.2 \pm 8.4$ & $21.3 \pm 11.4$ & $18.5 \pm 10.7$ & $14.6 \pm 3.3$ \\
\hline C22:6n-3 & $114.1 \pm 49.2$ & $128.3 \pm 36.5$ & $134.0 \pm 89.7$ & $126.1 \pm 48.8$ \\
\hline C24:0 & $16.1 \pm 7.9$ & $28.1 \pm 20.0$ & $22.6 \pm 10.0$ & $25.1 \pm 20.4$ \\
\hline
\end{tabular}

Lipids, lipoproteins, and apolipoprotein profile

TC, TG, HDL-cholesterol, LDL-cholesterol, apoAI, and apoB were quantified, and the HDL-cholesterol/LDL-cholesterol and apoAI/apoB ratios were calculated. The results are presented in Table 4. Two weeks of Ramadan diet did not have any effect on the parameters of lipids and lipoproteins studied but fasting for one month altered the plasma lipid and lipoprotein profile significantly. In fact, the concentrations of TC, LDL-cholesterol $(\mathrm{p}<0.01)$, and apoB $(\mathrm{p}<0.05)$ increased. Moreover, the apoAI/
apoB and HDL-cholesterol/LDL-cholesterol values decreased. However, while the first ratio varied significantly $(\mathrm{p}<0.05)$, the variation of the second one was not significant $(\mathrm{p}<0.1)$. One month after Ramadan, the lipids and lipoprotein profile had not normalized, and they showed the same change observed at the end of Ramadan.

\section{DISCUSSION}

Dietary recommendations specify that the intakes of carbohydrate, proteins, and fats should provide $50-55 \%, 15 \%$, and $30 \%$ of daily energy respectively.

\begin{tabular}{|lcccc|}
\hline \multicolumn{4}{|l|}{$\begin{array}{l}\text { Table 4. Pre-fasting, fasting, and post-fasting plasma concentrations of lipids, lipoproteins and } \\
\text { apolipoproteins }\end{array}$} \\
\hline Parameter & BR & R $(2$ weeks $)$ & R (4 weeks) & AR (4 weeks) \\
\hline TC & $4.4 \pm 0.5$ & $4.5 \pm 0.6$ & $5.0 \pm 0.7^{* *}$ & $4.9 \pm 0.9^{*}$ \\
TG & $1.1 \pm 0.5$ & $1.1 \pm 0.5$ & $1.1 \pm 0.3$ & $1.1 \pm 0.6$ \\
LDL & $1.0 \pm 0.2$ & $1.0 \pm 0.2$ & $1.0 \pm 0.3$ & $1.0 \pm 0.2$ \\
apoAI & $2.9 \pm 0.5$ & $2.9 \pm 0.9$ & $3.5 \pm 0.8^{* *}$ & $3.4 \pm 1.0^{*}$ \\
apoB & $1.4 \pm 0.2$ & $1.4 \pm 0.2$ & $1.3 \pm 0.2$ & $1.3 \pm 0.3$ \\
HDL/LDL & $0.8 \pm 0.2$ & $0.9 \pm 0.2^{*}$ & $0.9 \pm 0.1^{*}$ & $0.8 \pm 0.1$ \\
apoAI/apoB & $0.4 \pm 0.2$ & $0.3 \pm 0.2$ & $0.3 \pm 0.1$ & $0.3 \pm 0.1$ \\
\hline Values are expressed as means \pm standard error. Pre-fasting sampling was done in period included \\
between two days before Ramadan and the first day of Ramadan. After fasting, sampling was done 4 \\
weeks after Ramadan. The two fasting times and after fasting values were compared the pre-fasting \\
values; ${ }^{*}$ p $<0.05 ;{ }^{* *} p<0.01 ;$ apo=apolipoprotein; AR=Post-fasting; BR=Pre-fasting; CT=Total cholesterol; \\
HDL=High-density lipoprotein; LDL=Low-density lipoprotein; R=Fasting; TG=Triglycerides
\end{tabular}


Also, an intake of fats composed of $50 \%$ of MUFAs, $25 \%$ of PUFAs, and $25 \%$ of SFAs was recommended. Despite the minor differences, the habitual and Ramadan diets of this study were concordant with these recommendations. However, fewer carbohydrates and more proteins were consumed during Ramadan $(\mathrm{p}<0.01)$. Also, the Ramadan diet was characterized by higher levels of cholesterol, PUFAs, and vitamin E. The higher intakes of PUFAs and vitamin E could be attributed to the higher consumption of raw vegetable oil, especially olive oil, which has high vitamin $\mathrm{E}$ (present at $20-75 \mathrm{mg} / 100$ $\mathrm{g}$ of olive oil; unpublished results) and PUFAs. Since cholesterol comes from animal lipids which are particularly rich in SFAs, the absence of change of these acids concomitantly to cholesterol is remarkable. This contrast could be explained by the high consumption of certain alimentary products with a particular composition as the briks (fried eggs). Egg contains a high level of cholesterol, and it has more unsaturated fatty acids (UFAs) than SFAs (about two-thirds UFAs vs one-third SFAs) $(22,23)$.

In agreement with previous observations (2-12), fasting Ramadan causes a change of biological and anthropometric profiles. At the end of Ramadan, our subjects exhibited an increase in BMI. This variation was not significant but it could be a great change of major clinical significance. In fact, if every person gained +1 BMI in Ramadan of each year, the whole population would be obese. Fortunately, the BMI is probably normalized after Ramadan as indicated by its relative decrease one month after Ramadan.

A diet high in cholesterol and in fatty acids is associated with an increased risk of atherosclerosis. However, the real impact of alimentary fatty acids appears according to their nature and respective levels. The SFAs and trans-fatty acids (TFAs) are recognized favourable to CVDs while the PUFAs are generally considered antiatherogenic (24-28). However, the latter fatty acids have a complex relationship with atherosclerosis. In particular, they become atherogenic factors if they are consumed at a disproportional quantity compared to SFAs and/ or insufficiently protected against the oxidative process. The maximal beneficial action of PUFAs was reported for the PUFA/SFA ratio=1 (29). In connection with that, the Ramadan diet of the study subjects appears to be positive: first, because the PUFA/SFA ratio increased, and it went very close to the recommended value, and second, because of its improved potential of protection against the oxidative deterioration as suggested by the increase of vitamin $\mathrm{E}$ intake.

Several studies reported that the rates of various fatty acids in plasma reflected the rate in food $(30,31)$.
Consistent with these data, we found that levels of the PUFA and PUFA/SFA ratio varied similarly in the diet and plasma. The increase in PUFAs was primarily due to one of w6 which could express an increased consumption of raw vegetable oils, mainly olive oil. Consistent with this idea, oleic acid also increased.

It is commonly admitted that the high intake of alimentary SFAs, TFAs, and cholesterol is associated with an increase in total cholesterol, LDL-cholesterol, and apoB concentration and/or decrease of HDL-cholesterol $(24-27,32)$. As it was shown in the composition diets (Table 2), the intake of SFAs was unvaried in Ramadan. The total content of TFA in the diet was not determined and only C18:1trans was quantified in plasma. However, the fact that this TFA plasma level did not change during Ramadan, and the fact that our subjects did not consume more processed foods which are rich in TFA (as margarine) suggests that the intake of TFAs did not vary significantly during Ramadan. So, the increase of TC, LDL-cholesterol, and apoB and the reduction of apoAI/apoB ratio (Table 3 ) observed in our subjects during Ramadan could be attributed mainly to the high intake of cholesterol (33). The consumption of such amounts of cholesterol was previously associated with the formation of abnormal and cholesterol-enriched LDL (17). This does not seem to be the case in the study subjects because LDL-cholesterol/apoB was unchanged. Furthermore, we had not observed the reduction of TC and TC/HDL-cholesterol ratio in response to high intakes of PUFAs $(4,34)$ perhaps because of a higher hypercholesterolaemic effect of the consumed cholesterol. However, an inadequate quantity and/or quality of alimentary fatty acids must be considered.

The plasma lipid profile and CVD risk in mice are said to be sensitive to the diet ratio of $\omega 6$ PUFA to eicosapentaenoic acid (EPA, C20:5 $\omega 3$ ) and docosa-

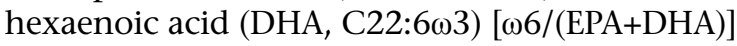
$(35,36)$. Both n-6 and n-3 PUFAs serve as precursors of other important compounds. Excess of one family of fatty acids can interfere with the metabolism of the other and its overall biological effects.

As is suggested by the increase of the $\omega 6 / \omega 3$ ratio (5.46 before Ramadan and 5.84-5.96 during Ramadan) in plasma lipids which reflects alimentary lipids $(18,19)$, Ramadan diet could have an unfavourable PUFA composition. Essentially, Ramadan is associated with an increased consumption of vegetable oil and a decrease in fish consumption.

The increase of n-6 PUFA in plasma lipids was justified by the concomitant increase of linoleic and 
arachidonic acids. The increase of these two acids was not surprising because they are metabolically linked (linoleic acid is the precursor of arachidonic acid). However, we must emphasize the more pronounced change of the second fatty acid as suggested by the more significant difference between its habitual and its Ramadan values $(\mathrm{p}<0.01 \mathrm{vs} \mathrm{p}<0.05$ for C18:2n-6) and by the decrease of the C18:2n-6/ C20:4n- 6 ratio which fell from about 6 before Ramadan to about 4.9 in Ramadan. Such an observation could be attributed, at least in part, to the activation of the linoleic acid to arachidonic acid, especially the absence of linolenic acid (C18:3 n-3), which is able to inhibit this conversion (37).

Now, it is well-known that the atherosclerotic process involves many and various mechanisms which are influenced by lipids or their derivatives. For example, the pattern of fatty acids (FAs) could affect the atherosclerosis risk by affecting the blood fluidity which depends on the production of prostaglandins obtained from arachidonic acid $(\omega 6)$. Also, the FA pattern, particularly the level of AA, has been reported to be important for the elasticity of arteries (38). An observed increase of n-6 in plasma could signify an adequate production of prostaglandins and correct elasticity of arteries and, then, a decrease of both blood clotting and calcification of arteries. On the other hand, high levels of PUFAs could be favourable to the atherogenic process. For example, they could stimulate the formation of adipocyte as it was in mouse (39) and, consequently, induce obesity, which is associated with a high risk of CVDs. Also, because PUFAs are highly sensitive to the oxidation process, the increase of their levels could be associated with an increased oxidative modification of LDL which becomes more atherogenic (40). However, this situation was not obligatory in our subjects because the concomitant higher intake of vitamin $\mathrm{E}$ could lead to a relative protection. In addition, in recent work, Mauerer et al. observed that linoleic acid reduced the ABCA1 and ABCG1 expression in M-CSF predifferentiated macrophages, and they concluded that it was associated with an increase of the formation of atherosclerotic lesions by diminishing the reverse cholesterol transport function of ABCA1 and ABCG1 (41). Finally, PUFAs affect the expression of genes controlling the inflammatory process which characterizes the atherosclerosis. In this respect, the n- 6 and n-3 families of PUFAs appear to have opposing and antagonistic effects. While n-3 PUFA increases the cells resistant to inflammation by eliminating the expression of inflammatory genes, n-6 PUFA exerts the opposite effect (42).

Considering the total data, the ratio of n-3 PUFA to n-6 PUFA appears as a determining factor for the protective role which has been proposed as an important index of cardiovascular risk. Based on the plasma fatty acid profile, this ratio may suffer an adverse change in Ramadan.

The return to habitual diet tends to restore the normal lipid and lipoprotein profile. However, the change, caused by Ramadan fasting, does not disappear four weeks after. It is possible that some eating and/or non-eating habits in Ramadan persist for some time later. A study of subjects during a longer time after Ramadan could have been very beneficial but it was difficult to retain the studied subjects for a longer period.

The interpretation of our results is delicate. Although the high intake of both vitamin E and PUFAs could have beneficial effects, the change of plasma lipid and lipoprotein profile was atherogenic (increase of plasma TC, LDL-cholesterol, apoB, and $\omega 6 / \omega 3)$.

In this paper, we provide evidence for the complexity of the relationship between Ramadan diet and the health state, particularly with atherosclerosis risk. To know the real effect of our subjects' Ramadan fasting model, it is notably necessary to study other parameters [Lp(a), apoAI-containing lipoproteins, TFAs, oxidant status, LDL size, etc.] and physiological functions (blood coagulation, platelets function, apoB-receptor activity, cholesterol efflux, etc.).

The knowledge about the effective impact of Ramadan fasting could be of great interest for possible intervention to correct the Ramadan diet of certain populations of practising Muslims.

The comparison of the dietary changes in different Islamic populations and of their impact on various biological and biochemical parameters may be a valid approach in determining a diet model to be followed by Muslims and to advise even nonMuslims.

\section{ACKNOWLEDGEMENTS}

This work was funded by the Ministry of High Education and Scientific Research, Tunisia. The authors thank all the volunteers who participated in the study. They also thank the hospital staff of the Centre Hospitalo-Universitaire, Habib Bourguiba of Sfax, for collecting the blood samples.

\section{REFERENCES}

1. Grundy SM, Denke MA. Dietary influences on serum lipids and lipoproteins. J Lipid Res 1990;31:1149-72.

2. Angel JF, Schwartz NE. Metabolic changes resulting from decreased meal frequency in adult male Muslims 
during the Ramadan fast. Nutr Rep Int 1975;11:2938.

3. Adlouni A, Ghalim N, Benslimane A, Lecerf JM, Saile R. Fasting during Ramadan induces marked increase in high-density lipoprotein cholesterol and decrease in low-density lipoprotein cholesterol. Ann Nutr Metab 1997;41:242-9.

4. Adlouni A, Ghalim N, Saile R, Had N, Parra HJ, Benslimane A. Beneficial effect on serum apoAI, apoB and LpAI levels of Ramadan fasting. Clin Chim Acta 1998;271:179-89.

5. Sarraf-Zadegan N, Atashi M, Naderi GA, Baghai AM, Asgary S, Fatehifar MR et al. The effect of fasting in Ramadan on the values and interrelations between biochemical, coagulation and hematological factors. Ann Saudi Med 2000;20:377-81.

6. Maislos M, Khamaysi N, Assali A, Abou-Rabiah Y, Zvili I, Shany S. Marked increase in plasma high-densitylipoprotein cholesterol after prolonged fasting during Ramadan. Am J Clin Nutr 1993;57:640-2.

7. Akanji AO, Mojiminiyi OA, Abdella N. Beneficial changes in serum apo A-1 and its ratio to apo B and HDL in stable hyperlipidaemic subjects after Ramadan fasting in Kuwait. Eur J Clin Nutr 2000;54:50813.

8. Saleh SA, El-Kemery TA, Farrag KA, Badawy MR, Sarkis $\mathrm{NN}$, Soliman FS et al. Ramadan fasting: relation to atherogenic risk among obese Muslims. J Egypt Public Health Assoc 2004;79:461-83.

9. Qujeq D, Bijani K, Kalavi K, Mohiti J, Aliakbarpour H. Effects of Ramadan fasting on serum low-density and high-density lipoprotein-cholesterol concentrations. Ann Saudi Med 2002;22:297-9.

10. Khaled BM, Bendahmane M, Belbraouet S. Ramadan fasting induces modifications of certain serum components in obese women with type 2 diabetes. Saudi Med J 2006;27:23-6.

11. Ziaee V, Razaei M, Ahmadinejad Z, Shaikh H, Yousefi $\mathrm{R}$, Yarmohammadi L et al. The changes of metabolic profile and weight during Ramadan fasting. Singapore Med J 2006;47:409-14.

12. Al-Hourani HM, Atoum MF. Body composition, nutrient intake and physical activity patterns in young women during Ramadan. Singapore Med J 2007; 48:906-10.

13. Beltaifa L, Bouguerra R, Ben Slama C, Jabrane H, ElKhadhi A, Ben Rayana MC et al. Food intake, and anthropometrical and biological parameters in adult Tunisians during fasting at Ramadan. East Mediterr Health J 2002;8:603-11.

14. Laaksonen DE, Nyyssonen K, Niskanen L, Rissanen $\mathrm{TH}$, Salonen JT. Prediction of cardiovascular mortality in middle-aged men by dietary and serum linoleic and polyunsaturated fatty acids. Arch Intern Med 2005;165:193-9.
15. Warensjo E, Sundstrom J, Vessby B, Cederholm T, Riserus U. Markers of dietary fat quality and fatty acid desaturation as predictors of total and cardiovascular mortality: a population-based prospective study. Am J Clin Nutr 2008;88:203-9.

16. Reaven P, Parthasarathy S, Grasse BJ, Miller E, Steinberg D, Witztum JL. Effects of oleate-rich and linoleate-rich diets on the susceptibility of low density lipoprotein to oxidative modification in mildly hypercholesterolemic subjects. J Clin Invest 1993;91:66876.

17. Maggi F, Falaschi F, Perani G, Frattoni A, Finardi G, Bellomo G. Oxidation of low-density lipoproteins. Correlation between reduced resistance in vitro and increased oxidation in vivo. Presse Med 1995;24:431-6.

18. Rosell MS, Lloyd-Wright Z, Appleby PN, Sanders TA, Allen NE, Key TJ. Long-chain n-3 polyunsaturated fatty acids in plasma in British meat-eating, vegetarian, and vegan men. Am J Clin Nutr 2005;82:327-34.

19. Sanders TA, Lewis F, Slaughter S, Griffin BA, Griffin M, Davies I et al. Effect of varying the ratio of n-6 to n-3 fatty acids by increasing the dietary intake of alpha-linolenic acid, eicosapentaenoic and docosahexaenoic acid, or both on fibrinogen and clotting factors VII and XII in persons aged 45-70 y: the OPTILIP Study. Am J Clin Nutr 2006;84:513-22.

20. Anderson SG, Sanders TA, Cruickshank JK. Plasma fatty acid composition as a predictor of arterial stiffness and mortality. Hypertension 2009;53:839-45.

21. Folch J, Lee M, Sloane-Stanley GH. A simple method for the isolation and purification of total lipids from animal tissues. J Biol Chem 1957;226:497-509.

22. Samman S, Piu Kung F, Carter LM, Foster MJ, Ahmad ZI Phuyal JL et al. Fatty acid composition of certified organic, conventional and omega-3 eggs. Food Chem 2009;116:911-4.

23. Pieroni G, Coste TC. Composition en acides gras des œufs : intérêt nutritionnel et valeur santé. Oléag Corps Gras Lipides 2009;116:911-4.

24. Walrand S, Fisch F, Bourre JM. Do saturated fatty acids have the same metabolic effect? Nutr Clin Metab 2010;24:63-75.

25. Chardigny JM, Corinne Malpuech-Brugere C. Trans and conjugated fatty acids: origins and nutritional effects. Nutr Clini Métabol 2007;21:46-51.

26. Huang Z, Wang B, Pace RD, Yoon S. Trans fat intake lowers total cholesterol and high-density lipoprotein cholesterol levels without changing insulin sensitivity index in Wistar rats. Nutr Res 2009;29:206-12.

27. Judd JT, Baer DJ, Clevidence BA, Kris-Etherton P, Muesing RA, Iwane M. Dietary cis and trans monounsaturated and saturated FA and plasma lipids and lipoproteins in men. Lipids 2002;37:123-31. 
28. Schlienger JL. Nutrition et dylipoprotéinémie. Rev Franç Lab 2001;334:51-4.

29. Monnier L, Avignon A, Colette C, Pipemo M. Prévention primaire nutritionnelle et medicamenteuse de l'athérosclérose. Rev Med Int 1999;20:360-70.

30. Lopez SM, Trimbo SL, Mascioli EA, Blackburn GL. Human plasma fatty acid variations and how they are related to dietary intake. Am J Clin Nutr 1991;53:62837.

31. Ma J, Folsom AR, Shahar E, Eckfeldt JH. Plasma fatty acid composition as an indicator of habitual dietary fat intake in middle-aged adults. The Atherosclerosis Risk in Communities (ARIC) Study Investigators. Am J Clin Nutr 1995;62:564-71.

32. Torres-Gonzalez M, Volek JS, Sharman M, Contois JH, Fernandez ML. Dietary carbohydrate and cholesterol influence the number of particles and distributions of lipoprotein subfractions in guinea pigs. J Nutr Biochem 2006;17:773-9.

33. Zanni EE, Zannis VI, Blum CB. Effect of egg cholesterol and dietary fats on plasma lipids, lipoproteins and apoproteins of normal women consuming natural diets. J Lipid Res 1987;28:18-27.

34. Kris-Etherton PM, Yu S. Individual fatty acid effects on plasma lipids and lipoproteins: human studies. Am J Clin Nutr 1997;65:1628-44.

35. Wang S, Wu D, Matthan NR, Lamon-Fava S, Lecker JL, Lichtenstein AH. Reduction in dietary omega-6 polyunsaturated fatty acids: eicosapentaenoic acid plus docosahexaenoic acid ratio minimizes atherosclerotic lesion formation and inflammatory response in the LDL receptor null mouse. Atherosclerosis 2009;204:147-55.

36. Sheril A, Jeyakumar SM, Jayashree T, Giridharan NV, Vajreswari A. Impact of feeding polyunsaturated fatty acids on cholesterol metabolism of dyslipidemic obese rats of WNIN/GR-Ob strain. Atherosclerosis 2009;204:136-40.

37. Blond J P, Poisson JP, Lemarchal P. Acide $\alpha$-Iinolénique alimentaire et pression artérielle chez le rat. Arch Physiol Biochem 1980;88:147-53.

38. Anderson SG, Sanders TAB, Cruickshank JK. Plasma fatty acid composition as predictor of arterial stiffness and mortality. Hypertension 2009,53:839-45.

39. Ailhaud G. Lipides alimentaires et masse adipeuse excédentaire : le statut des acides gras w6 et w3 n'est plus ce qu'il était. Obesity 2007;2:155-7.

40. Matsuura E, Hughes GR, Khamashta MA. Oxidation of LDL and its clinical implication. Autoimmun Rev 2008;7:558-66.

41. Mauerer R, Ebert S, Langmann T. High glucose, unsaturated and saturated fatty acids differentially regulate expression of ATP-binding cassette transporters ABCA1 and ABCG1 in human macrophages. Exp Mol Med 2009,41:126-32.

42. Wang L, Lim EJ, Toborek M, Hennig B. The role of fatty acids and caveolin-1 in tumor necrosis factor alpha-induced endothelial cell activation. Metabolism 2008;57:1328-39. 